\title{
Controlled trial of respiratory health worker visiting patients with chronic respiratory disability
}

\author{
A COCKCROFT, P BAGNALL, A HESLOP, N ANDERSSON, R HEATON, J BATSTONE, \\ J ALLEN, P SPENCER, A GUZ
}

\begin{abstract}
Seventy five patients with chronic respiratory disability were randomised to a group visited by a respiratory health worker (42) or control group (33). The first group was visited monthly by a respiratory nurse, who gave education and support. The effect of the intervention was assessed in terms of quality of life (by questionnaires), the number and duration of admissions to hospital, and the number of deaths. The questionnaires on quality of life showed no changes in either group during the study, but nearly all of the group visited by a respiratory health worker said that they valued the visits and wished them to continue. Their knowledge about their condition also improved compared with that of the controls. The duration of stay in hospital for respiratory reasons in the group visited by a respiratory health worker was longer than that of control patients. This was explained by their being scored as more ill than the controls on
\end{abstract}

Department of Medicine, Charing Cross and Westminster Medical School, London W6 8RF

A COCKCROFT, $M D, M R C P$, lecturer in medicine

P BAGNALL, SRN, research fellow

A HESLOP, SRN, DN, research fellow

R HEATON, MD, MRCP, senior registrar

A GUZ, MD, FRCP, professor of medicine

Trades Union Congress Centenary Institute of Occupational Health, London School of Hygiene and Tropical Medicine, London WC1

N ANDERSSON, MFCM, MSC, lecturer

Department of Community Medicine, Westminster Hospital, London SW1 J BATSTONE, MB, CHB, registrar

J ALLEN, MB, BS, registrar

P SPENCER, MB, PHD, registrar

Correspondence to: Dr Cockcroft. admission. Fewer patients died in the group visited by a respiratory health worker than in the control group $(p=0.11)$.

The patients in the group visited by respiratory health workers may have survived longer because they sought help rather than dying at home. If confirmed this could have implications for the cost of their care.

\section{Introduction}

Chronic respiratory disease is an important cause of disability, especially in older people. Such people can now be kept alive for longer, but their quality of life may be poor, as recognised in the report of a working party of the Royal College of Physicians. ${ }^{1}$ Its report recommended that posts for respiratory health workers should be created to help with the care of people with chronic respiratory diseases at home. It emphasised that trial appointments should be made first and their efficacy assessed by comparison with a control group.

Our study attempted to follow these recommendations. The role of a nurse visiting respiratory patients at home as part of a home care team has been described in reports from the United States and Canada, ${ }^{23}$ but these were not controlled trials and transatlantic medical practices differ. This is the first attempt to evaluate the role of respiratory health workers in a controlled trial.

\section{Patients and methods}

\section{PATIENTS}

All the patients suffered from chronic respiratory disability that was caused mainly by chronic obstructive airways disease. Patients who had been admitted to hospital at least twice during the previous three years and new patients who had been seen within the past year were eligible for the study. Those whose disability was not caused by a respiratory condition and those 
unable to understand questionnaires were excluded. Consent was obtained from the general practitioners, and 92 patients were sent a letter: 79 agreed to participate, two were excluded, and two died, leaving 75 to be randomised to the group visited by a respiratory health worker (42) or the control group (33). Randomisation was stratified according to the number of admissions to hospital in the previous three years.

\section{ASSESSMENTS}

Outside hospital-Patients were assessed twice (November 1984 and August 1985) by questionnaires administered by two doctors (JB and JA) who did not otherwise participate in the study. The questionnaires comprised: the version of the general health questionnaire with 28 questions, ${ }^{4}$ intended to give a general assessment of mental health; a questionnaire concerning mobility, knowledge about condition, and medicines, designed for this study; and a set of visual analogue scales concerning physical and psychological aspects of the patients' lives, also designed for the study. The assessors also rated the patients' degree of disability and distress and measured peak expiratory flow rate. The patients' knowledge of their condition and medicines was assessed by two independent doctors. They scored knowledge as being good, adequate, or poor and, given the pair of questionnaires filled in by each patient, recorded changes in knowledge as improved, the same, or worse. General practitioners were sent cards for recording remarks about consultations that they held with patients in the study.

Hospital admissions and deaths-The dates on which patients were admitted to and discharged from hospital were obtained from hospital records, and the patients' notes were reviewed by a respiratory specialist (RH) who did not otherwise participate in the study. He decided whether cases admitted were respiratory or non-respiratory and assessed how ill each

TABLE I-Sex, age, respiratory details, and smoking history of patients at beginning of study

\begin{tabular}{lcc}
\hline & $\begin{array}{c}\text { Group visited by } \\
\text { respiratory health } \\
\text { worker } \\
(\mathrm{n}=42)^{\star}\end{array}$ & $\begin{array}{c}\text { Control group } \\
(\mathrm{n}=33)\end{array}$ \\
\hline M:F & $29: 13$ & $22: 11$ \\
Mean age (years) (range) & $69 \cdot 2(46-84)$ & $70 \cdot 5(51-84)$ \\
Mean (SD) forced expiratory volume (1) & $0 \cdot 78(0 \cdot 31)$ & $0 \cdot 88(0 \cdot 43)$ \\
Mean (SD) peak expiratory flow rate (1/min) & $202(97)$ & $206(96)$ \\
Smoking history: & 1 & 1 \\
Heavy smokers & 13 & 5 \\
Light smokers & 25 & 26 \\
Ex-smokers & 3 & 1 \\
Non-smokers & $1 \cdot 9(2 \cdot 4)$ & $1 \cdot 8(2 \cdot 1)$ \\
Mean (SD) No of admissions in past three years & & \\
\hline
\end{tabular}

^ Two died before first visit by respiratory health worker.

TABLE II-Patients' knowledge about conditions and medicines. Values are numbers of patients

\begin{tabular}{|c|c|c|c|c|}
\hline & \multicolumn{2}{|c|}{ Knowledge about condition } & \multicolumn{2}{|c|}{ Knowledge about medicines } \\
\hline & $\begin{array}{l}\text { Group visited by } \\
\text { respiratory } \\
\text { health worker }\end{array}$ & $\begin{array}{l}\text { Control } \\
\text { group }\end{array}$ & $\begin{array}{l}\text { Group visited by } \\
\text { respiratory } \\
\text { health worker }\end{array}$ & $\begin{array}{l}\text { Control } \\
\text { group }\end{array}$ \\
\hline \multicolumn{5}{|c|}{ At beginning of study } \\
\hline $\begin{array}{l}\text { Judgment of first doctor: } \\
\text { Poor } \\
\text { Adequate } \\
\text { Good }\end{array}$ & $\begin{array}{l}13^{\star} \\
12 \\
16\end{array}$ & $\begin{array}{r}6 \\
10 \\
17\end{array}$ & $\begin{array}{r}8 \\
14 \\
20\end{array}$ & $\begin{array}{l}10 \\
10 \\
13\end{array}$ \\
\hline $\begin{array}{l}\text { Judgment of second docto } \\
\text { Poor } \\
\text { Adequate } \\
\text { Good }\end{array}$ & $\begin{array}{r}5 \\
16 \\
20\end{array}$ & $\begin{array}{r}6 \\
7 \\
20\end{array}$ & $\begin{array}{r}8 \\
8 \\
26\end{array}$ & $\begin{array}{r}8 \\
7 \\
18\end{array}$ \\
\hline \multicolumn{5}{|c|}{ Changes during studyt } \\
\hline $\begin{array}{l}\text { Judgment of first doctor: } \\
\text { Worse } \\
\text { Same } \\
\text { Better }\end{array}$ & $\begin{array}{r}3 \\
15 \\
14\end{array}$ & $\begin{array}{r}2 \\
15 \\
6\end{array}$ & $\begin{array}{r}4 \\
15 \\
17\end{array}$ & $\begin{array}{r}2 \\
16 \\
7\end{array}$ \\
\hline $\begin{array}{l}\text { Judgment of second docto } \\
\text { Worse } \\
\text { Same } \\
\text { Better }\end{array}$ & $\begin{array}{r}3 \\
15 \\
14\end{array}$ & $\begin{array}{r}0 \\
19 \\
4\end{array}$ & $\begin{array}{r}2 \\
24 \\
10\end{array}$ & $\begin{array}{r}3 \\
17 \\
5\end{array}$ \\
\hline
\end{tabular}

* One person did not answer questions about knowledge of condition on first questionnaire. $\dagger$ Only those who had adequately completed questionnaire on both occasions scored for change. patient had been on admission on a scale of increasing severity from one to five. Deaths during the study were recorded with date, cause of death (respiratory or non-respiratory), and whether they occurred at home or in hospital.

Assessments in group visited by respiratory health worker-The respiratory health worker recorded how many of the initial goals were achieved. Patients were asked if they wanted further visits when the project funding was extended, and a doctor (AC) visited them to ask them about the quality of care that they had received.

\section{INTERVENTION}

General practitioners and hospital doctors were not aware of their patients' group allocation. The post of respiratory health worker was filled by two nurses (AH and PB) who had had experience of dealing with respiratory patients in both hospital and community settings. They visited patients about once a month, and their work was mainly educative and supportive, focusing on health rather than on disease, and varying in content according to individual needs. They structured their intervention to follow a model that entailed identifying problems in activities of daily living and setting goals to increase independence in these activities. ${ }^{6}$ Patients were encouraged to recognise signs of deterioration in their health and take appropriate action, including contacting the doctor if necessary. The nurses did not contact the doctor themselves except in an emergency (this occurred only once). They were supported by a consultant chest specialist and a consultant psychotherapist who were independent of the study.

\section{ANALYSIS}

The group attended by a respiratory health worker was compared with the control group, and the significance of differences between them was tested with unpaired $t$ tests and $\chi^{2}$ tests. The numbers of patients who were admitted to hospital and who died were compared by looking at the occurrence of each of these events in the two groups, taking into account the number of people in the groups and by looking at the occurrence of such events in each group per person days at risk. Two patients died and six were admitted to hospital in the group attended by a respiratory health worker after the first assessment but before the first visit of the nurse; these cases are analysed separately from events that occurred after the first visit by the respiratory health worker. Events that occurred during an equivalent period in the control group were also identified (see footnote to table III).

\section{Results}

The groups were not significantly different in terms of sex ratio, age, forced expiratory volume in one second, peak expiratory flow rate, smoking habits, and number of previous admissions to hospital on entry (table I). The peak expiratory flow rate was not significantly different by the end of the study in either group.

\section{OUTSIDE HOSPITAL}

The questionnaires about the quality of life did not show any significant differences between the groups at the time of the first assessment, and no significant changes occurred in either group during the study. Similarly, neither the ratings of disability and distress made by the outside assessors nor the composite scores derived from these ${ }^{5}$ differed initially between the groups or changed significantly in either group during the study. The groups did not differ significantly in their knowledge about their condition or medicines at the beginning of the study (table II), but more people in the group attended by a respiratory health worker than in the control group improved their knowledge about their condition (relative risk (RR) 1.39, $95 \%$ confidence interval (CI) $1 \cdot 1$ to $1 \cdot 9$ ). A similar trend was seen for knowledge about medicines (RR $1 \cdot 19,90 \%$ CI 0.99 to $1 \cdot 42$ ) (table II). Four people in the group attended by a respiratory health worker gave up smoking, and one heavy smoker became a light smoker. In the control group no one stopped smoking, and two ex-smokers started smoking again. It was not possible to assess the number of consultations with general practitioners as few general practitioners returned the consultation cards.

\section{HOSPITAL ADMISSIONS AND DEATHS}

The number of patients admitted to hospital during the study, whether for respiratory or non-respiratory causes, did not differ significantly between 
the groups (table III). The group attended by a respiratory health worker spent a significantly greater proportion of its time, after the worker's first visit, in hospital for respiratory causes than the control group (RR 3.26, $95 \%$ CI 2.6 to 4.0 ). The difference between the groups in the number of patients admitted for non-respiratory causes was not significant. The duration of stay of patients admitted for respiratory reasons was significantly greater in the group attended by a respiratory health worker than in the control group (RR $2 \cdot 79,95 \%$ CI $1 \cdot 38$ to $5 \cdot 64$ ) (table IV), but the duration of stay of patients admitted for non-respiratory reasons did not differ between the groups. Of the patients who were admitted for respiratory problems and

TABLE III-Number of admissions to hospital, duration of stay, and number of deaths during study

\begin{tabular}{|c|c|c|c|}
\hline & \multicolumn{2}{|c|}{$\begin{array}{l}\text { Group attended by } \\
\text { respiratory health worker }\end{array}$} & \multirow[b]{2}{*}{$\begin{array}{c}\text { Control group } \\
(n=33)\end{array}$} \\
\hline & $\begin{array}{l}\text { Before first visit } \\
(n=42)^{\star}\end{array}$ & $\begin{array}{l}\text { After first visit } \\
\quad(n=40)\end{array}$ & \\
\hline \multicolumn{4}{|c|}{ Admissions to hospital } \\
\hline No of hospital admissions: & \multirow{3}{*}{6} & \multirow{3}{*}{$\begin{array}{r}16 \\
9\end{array}$} & \multirow{3}{*}{$\begin{array}{r}11 \\
6\end{array}$} \\
\hline Respiratory cause & & & \\
\hline Non-respiratory cause & & & \\
\hline No of person days at risk $\dagger$ & 1436 & 8417 & 7802 \\
\hline \multicolumn{4}{|c|}{ Duration of stay in hospital } \\
\hline No of person days in hospitalł: & \multirow{3}{*}{75} & & \multirow{3}{*}{$\begin{array}{l}96 \\
74\end{array}$} \\
\hline $\begin{array}{l}\text { Respiratory cause } \\
\text { Non-respiratory cause }\end{array}$ & & 349 & \\
\hline Non-respiratory cause & & 122 & \\
\hline No of person days at risk $₫$ & 1511 & 8888 & 7972 \\
\hline \multicolumn{4}{|c|}{ Deaths during study } \\
\hline No of deaths & 2 & 3 & 7 \\
\hline Person days at risk $\oint$ & 1511 & 8888 & 7952 \\
\hline
\end{tabular}

* Number of people in group attended by respiratory health worker (before first visit) cannot be compared with numbers in other groups, as this group existed for only a short period. A period equivalent to that between the first assessment and the first visit by a respiratory health worker in the first 33 patients in the group attended by respiratory health worker was calculated for the 33 control patients. During this period one control patient was admitted to hospital for respiratory problems and died. Exclusion of these events did not affect substantially the above analysis.

t Sum of number of days spent by each person in study minus number of days in hospital.

+ Sum of number of days spent by each person in hospital.

S Sum of number of days spent by each person in study.

TABLE IV-Duration of stays in hospital during study. Values are numbers of admissions

\begin{tabular}{|c|c|c|c|c|}
\hline & \multicolumn{4}{|c|}{ Duration of stay (days) } \\
\hline & \multicolumn{2}{|l|}{$\leqslant 10$} & \multicolumn{2}{|l|}{$\geqslant 11$} \\
\hline & $\begin{array}{l}\text { Group visited by } \\
\text { respiratory } \\
\text { health worker }\end{array}$ & Controls & $\begin{array}{l}\text { Group visited by } \\
\text { respiratory } \\
\text { health worker }\end{array}$ & Controls \\
\hline $\begin{array}{l}\text { Total No of admissions } \\
\text { for respiratory illness } \\
\text { Admissions graded for }\end{array}$ & 4 & 9 & 12 & 2 \\
\hline $\begin{array}{l}\text { severity of illness: } \\
1 \text { or } 2 \\
3 \text { or } 4\end{array}$ & $\begin{array}{l}2 \\
1\end{array}$ & 5 & 7 & 2 \\
\hline $\begin{array}{l}\text { Total No of admissions for } \\
\text { non-respiratory illness: }\end{array}$ & 4 & 2 & 5 & 4 \\
\hline
\end{tabular}

Admissions before first visit of respiratory health worker excluded. Excluding one control patient admitted during equivalent period made no substantial difference to results. Admissions ending in death are excluded.

survived, those who had been visited by a respiratory health worker were scored as being more ill than the control patients (RR $6.22,95 \% \mathrm{CI} 1.6$ to $24 \cdot 5)$ (table IV). Severity of illness on admission was associated significantly with duration of stay (RR $3 \cdot 45,95 \%$ CI $1 \cdot 2$ to $10 \cdot 0$ ) (table IV). When admissions were stratified by severity of illness the association between the group visited by the respiratory health worker and the duration of stay in hospital for respiratory problems was no longer significant (table IV).

There were fewer deaths in the group visited by a respiratory health worker (after the first visit) than in the control group or in the control group and group visited by a respiratory health worker (before the first visit) combined ( $\mathrm{p}=0 \cdot 11$ ) (RR $0 \cdot 36,90 \% \mathrm{CI} 0 \cdot 1$ to $1 \cdot 0$, comparing deaths/person days at risk in the group visited by a respiratory health worker (after the first visit) with those in the control group and group and visited by a respiratory health worker (before the first visit) combined) (table III). All deaths in the group visited by a respiratory health worker (after the first visit) occurred in hospital, whereas four of the seven deaths in the control group and one of the two in the group visited by a respiratory health worker (before the first visit) occurred at home.

\section{ASSESSMENTS BY RESPIRATORY HEALTH WORKER}

Of $\mathbf{3 3 5}$ goals set in the $\mathbf{4 0}$ patients visited (about eight per person), 258 $(77 \%)$ were considered by the respiratory health worker to have been achieved. Four months after the study 33 of the 36 people $(92 \%)$ who remained alive said that they wished to have further visits. Twenty five of the 31 remaining people visited later by a doctor (AC) thought that they had benefited from the visits by a respiratory health worker and had clearly enjoyed them.

\section{Discussion}

The questionnaires used to assess the quality of life of the patients in this study gave disappointing results. This is probably because of the relative insensitivity of this method. All the patients were disabled with a progressive disease, and actual physical improvement or substantial change in their life circumstances was unlikely. The questionnaires rely necessarily on standard questions, but what contributes to quality of life may vary greatly among people. Problems of measuring quality of life are common in clinical trials.

A better idea of the impact of the intervention is given by the almost universal wish of the patients for further visits, suggesting that they were valued. Most patients perceived the visits as being useful and considered that they had received a better quality of care than before. Increasing attention is being paid to satisfaction of patients with health services, and our results suggest that personal attention of this sort can improve satisfaction.

Education was a large part of the job of the respiratory health worker, and they were successful at this. People feel more relaxed in their own homes, and this is more conducive to learning than the tense, rushed outpatient department or hospital ward. Many people emphasised that the repeated message on subsequent visits had helped their learning. We cannot be certain of the benefit of the patients' improved knowledge, but few would now argue that it is not a good thing for patients to be more knowledgeable.

Fewer people in the group visited by a respiratory health worker died during the study, but the duration of their stays in hospital for respiratory problems was longer than for those in the control group. This might be because very ill people in the control group died at home (four of the seven deaths were at home), whereas those in the group visited by a respiratory health worker sought help and were admitted to hospital, remaining there for a long time because they were so ill but surviving. This idea is supported by the finding that patients in the group visited by a respiratory health worker were more ill than controls on admission for respiratory causes and thus stayed in for longer. The results also imply that fewer less severely ill patients in the group visited by a respiratory health worker were being admitted to hospital than similar patients in the control group. Thus some control patients may have been admitted "unnecessarily," yet others may have died at home when admission could have saved their lives. These interpretations of our data are offered tentatively, as they are based on small numbers, and other explanations are possible. There may have been an imbalance towards more severely ill patients in the group visited by a respiratory health worker, but the apparently fewer deaths in this group makes this unlikely.

The results of this study suggest that intervention by a respiratory health worker can keep patients with respiratory problems alive for longer but may increase the costs to the health service of looking after them. We believe that these findings are interesting enough to warrant a larger study.

We are grateful to Dr N Cooke and Dr J Denford for medical and psychiatric advice; to Dr K MacRae for statistical advice; to Dr I Arnold for reviewing patients' notes and scoring questionnaire replies; and to Dr W A Seed and Dr P D Snashall for allowing us to include their patients in the study. 
References

1 Royal College of Physicians. Disabling chest disease: prevention and care. $f R$ Coll Physicians Lond 1981;15:69-87.

2 Petty TL, Nett LM, Finigan MM, Brink GA, Corsello PR. A comprehensive care programme for chronic airway obstruction. Methods and preliminary evaluation of symptomatic and functional improvement. Ann Intern Med 1969;70:1109-20.

3 Cherniack RM, Handford RG, Svanhill E. Home care of chronic respiratory disease. JAMA 1969;208:821-4.

4 Goldberg DP, Hillier VF. A scaled version of the general health questionnaire. Psychol Med 1978;8:1-7.
5 Rosser RM. A set of descriptions and a psychometric scale of severity of illness: an indicator for use in evaluating the outcome of hospital care. London: University of London, 1980. (Thesis.) 6 Roper N, Logan W, Tierney AJ. Using a model for nursing. Edinburgh: Churchill Livingstone, 1983.

7 Van Dam FSAM, Linssen CAG, Couzijn AL. Evaluating 'quality of life' in cancer clinical trials. In: C Buyse ME, Staquet MJ, Sylvester RJ, eds. Cancer clinical trials. Methods and practice. Oxford: Oxford University Press, 1984:27-43.

(Accepted 12 November 1986)

\title{
Early emergency care study: the potential and benefits of advanced prehospital care
}

\author{
I W R ANDERSON， R J BLACK， I MCA LEDINGHAM， K LITTLE, C E ROBERTSON, \\ J D URQUHART
}

\begin{abstract}
Of 26358 patients taken by ambulance to the accident and emergency departments of two large hospitals, 1185 were admitted to resuscitation areas. The scope for ambulance staff to employ a range of advanced techniques at the scene of incidents was assessed by using information relating to the condition of patients when they were picked up by the ambulance and on admission, time in transit, details from hospital records, and outcome at three months. For non-survivors further assessment was made of the benefit, in terms of survival, which might have accrued had advanced techniques been used.

The results of the assessment of benefit were compared with estimates of benefit from other studies. In cases of cardiopulmonary arrest the potential to save lives was less optimistic than earlier estimates, and in cases of trauma the potential to save lives was negligible.
\end{abstract}

Victoria Infirmary, Glasgow

I W R ANDERSON, FRCS, consultant in accident and emergency medicine and surgery

Information Services Division, Scottish Health Service CSA, Trinity Park House, Edinburgh EH5 3SQ

R J BLACK, MA, research officer

J D URQUHART, MSC, principal research officer

University Department of Surgery, Western Infirmary, Glasgow

I MCA LEDINGHAM, MD, professor of intensive care

Royal Infirmary, Edinburgh

K LITTLE, MD, consultant in accident and emergency medicine and surgery

Royal Infirmary and Western General Hospital, Edinburgh

C E ROBERTSON, MRCP, consultant in accident and emergency medicine and surgery

Correspondence to Mr J D Urquhart.

Other members of the Scottish Early Emergency Care Group are:

M Begley; D Carrington, FASI; G Dickson; B Duncan, MSC; L Guest; J Hamilton; M A Heasman, FRCPE; J Hollingworth SRN; S A K Kerr, PHD; A Patel, FRCP; F Thomson; J M Wilby, FASI.

\section{Introduction}

Specialist ambulance schemes have been evaluated in a number of centres in the United Kingdom, ${ }^{1.5}$ and extended training has already been introduced by a number of ambulance services. ${ }^{6}$ There may be a good theoretical basis from which to argue that patients admitted to accident and emergency departments could benefit from advanced. training, but estimates of such benefit have so far been based on limited evidence. In previous studies the ability of ambulance staff to achieve successful outcomes without advanced training has not been fully taken into account.

This study describes patterns of illness and injury, the early $\mathbb{\mathbb { D }}$ emergency care currently provided by ambulance staff, and out- $\vec{F}$ comes for patients transported by ambulance to two accident and emergency departments serving urban and semiurban areas. These departments serve a combined catchment population which is estimated to be 0.95 million. Information from the study provides the basis for an evaluation of the scope for further intervention by ambulance staff with advanced training and the benefits, in terms of patient survival, which could be achieved. This evaluation has important implications for extended training schemes.

\section{Methods}

The study population comprised all patients taken by ambulance to the accident and emergency departments of Edinburgh Royal Infirmary and Glasgow Western Infirmary during the 12 months from 1 April 1984 to 31 March 1985. With rare exceptions children were not included in the study because they were treated in accident and emergency departments in specific $\omega$ children's hospitals.

Details of transportation times and the locations of incidents were 0 obtained from ambulance log sheets. In Edinburgh ambulance staff $\frac{D}{D}$ recorded information relating to the condition of patients when they were $\stackrel{\mathscr{P}}{+}$ picked up by the ambulance (uplift) using a descriptive system derived from 0 the triage index. ${ }^{7}$ The descriptive method used was based on observations of the patients' conscious state, respirator effort, capillary refill, eye opening, $\mathbb{D}$ verbal response, and motor response. Information was also recorded on the $\overrightarrow{\mathbb{D}}$ use of techniques which are currently used by ambulance staff in Scotland $\stackrel{\square}{2}$ such as oropharangeal airway management, artificial ventilation, oxygen treatment, and cardiac massage.

Further information was collected by accident and emergency medical $\frac{\delta}{0}$ staff on all patients admitted to the resuscitation areas of both hospitals and on a sample of other patients admitted to Glasgow Western Infirmary. This 